\title{
Analytical Hierarchy Process Model for Vendor Selection
}

\author{
Muhammad Fariz Tiowiradin ${ }^{1, *}$ Nurmala $^{1}$
}

\author{
${ }^{1}$ University of Indonesia, Faculty of Economics and Business, Jakarta, Indonesia \\ *Corresponding author. Email: muhammad.fariz82@ui.ac.id
}

\begin{abstract}
The selection of vendors in Supply Chain Management is crucial in every company because it will help companies in dealing with global problems where the selection of the right vendor will have a significant impact on company efficiency. The purpose of this study is to determine the priority order of the criteria that influence the selection of vendors for operational vehicles and to analyze these criteria so that alternative vendors should be chosen by the company, by taking a case study at an oil drilling company in Indonesia. This study implements the Analytical Hierarchy Process (AHP) method by using 5 (five) criteria identified through the Systematic Literature Review (SLR) method, namely Quality, Delivery, Cost, Service, and Information Technology. The use of criteria in this study is combined with 4 (four) alternative vendors who have become partners with an oil drilling company in Indonesia. The results showed that the most significant criterion in the selection process was the Service criterion, and PMS was chosen as the vendor of operational vehicle suppliers at oil drilling company in Indonesia based on the priority value of the supplier is the largest. This research will contribute to the company in selecting vendors based on decision making by considering various criteria.
\end{abstract}

Keywords-Analytical hierarchy process, Decision making, Supply chain management, Selection criteria.

\section{INTRODUCTION}

The procurement of goods/services has an important role in the implementation of company operations in improving the effectiveness of the work and business development of the company. Procurement of goods/services needs to be done quickly, flexibly, efficiently, and effectively in order to avoid the risk of losing business momentum that has the potential to cause harm to the company. The optimization of the process of Procurement of goods/services needs to be done as an effort to increase company profits from the aspect of reducing the cost of procurement of goods/services while continuing to support the company's operations in quality, availability, and delivery.

One major aspect of the purchasing function is vendor selection. Supplier selection becomes even more important in supply chains in view of several supply chain trading partners and stakeholders involved in it [1]. Supplier selection is basically a multiple criteria decision-making (MCDM) problem. There are two aspects of the problem in the supplier selection, the first aspect is the criteria for evaluation of suppliers, and the other aspect is the procedure or method of supplier selection [2]. Different companies may have different organizations and cultural backgrounds, which may also affect the operation in supplier selection. Therefore, which criteria are suitable and should be used for the evaluation of suppliers in supply chain management (SCM) for an enterprise is crucial. On the other aspect, with so many criteria and different suppliers, how to choose a suitable and right supplier is equally important.

This study uses the AHP method. Data collection will be done through observation, focus group discussion, and literature study in order to find a relationship between the quality of the evaluation criteria on the resulting performance. Data processing is done by searching the results of calculations based on the results of data comparison with weighting values in order to get priority levels in grouping output results. The output of the AHP method can predict performance and classify vendor ratings based on index values and vendor criteria used. The AHP method uses existing data that are qualitative based on perceptions, experiences, intuition from experts so that they can predict criteria with a high degree of accuracy. 
The paper proceeds as follows. In section 2, the material and methods related to this research are explored. Then, the results are presented in section 3 . Discussion, conclusion, research implication, and managerial implications are presented in the section 4 .

\section{MATERIALS AND METHODS}

\subsection{Materials Collection: Systematic Literature Review}

To conduct a comprehensive analysis of existing research on a given topic, a systematic approach must be carried out and the existing methodology must be reviewed in such a way that will produce a solid basis for the rest of the research. The analysis can be carried out by performing different methods and approaches, such as systematic literature reviews or systematic mapping studies as in [3]. A systematic literature review is a means of evaluating and interpreting all available research relevant to a research question, topic area, or phenomenon of interest. Systematic reviews aim to present a fair evaluation of a research topic by using a trustworthy, rigorous, and auditable methodology [3].

In this step, the material to be analyzed is delimited and the unit of analysis is defined. To ensure that only rigorous studies we captured in our review, we delimited our search to articles published in English-language impact factor journals. We further delimited our search by employing keywords based on the key constructs that inform our research questions: AHP, automotive, and later. The search was performed on the ProQuest database using the following keyword strings:

1. ("Supplier" OR "vendor") AND ("selection" OR "procurement") AND ("factor" OR "criteria")

2. ("Supplier" OR "vendor") AND ("selection criteria" OR "procurement criteria")

3. ("Supplier" OR "vendor") AND ("selection criteria" OR "procurement criteria") AND ("AHP") AND ("AUTOMOTIVE")

A total of 399,336 publications identified from the first keyword search. These search results are still too general and more specific keywords are needed to minimize the scope of the literature search with the second search string. In the second search, 33,384 publications were obtained. These search results are fewer and more specific than the first search results, but these results are still too general so that searches are still needed with more specific keywords to minimize the scope of the literature search. A total of 538 articles resulted from the third keyword search. After removing duplicates and non-peer-reviewed publications, 222 articles remained for further evaluation.
Then the abstracts of these 222 articles are reviewed to assess if they fit with the research questions. In the search we targeted papers published in the last 5 years from 2020, and 143 publications relevant for further review. We excluded a non-article paper from further analysis, this reduced the article dataset from 143 to 134 articles considered for further review. To illustrate how references were used to identify additional articles, we take article [4] as an example. After getting the results of the search carried out in the previous phase, the next step is to do a quick reading of the title, abstract, and research methodology for the 134 articles to get the most relevant articles and in accordance with the topics raised in this study. Based on this process, 11 articles were most relevant to this research topic. Next is conducting a literature review by looking for the criteria used in the selection of suppliers and the method of approach used in each literature. From the results of this literature review, 30 criteria were used to select suppliers. These criteria will be analyzed based on the highest number of each criterion that appears and is used as an influential factor in the selection of suppliers. Figure 3 summarizes the search and evaluation process for the final article set considered for analysis. Table 9 summarizes the Literature on Supplier Selection and the Analysis Approaches. The List of Selection Criteria is presented in Table 10.

Based on the analysis of the literature review process, 5 criterias with the highest number of uses obtained and used as the main criteria for supplier selection in this study, including Quality which is mentioned in 6 articles, Delivery with a total of 5 articles, Cost with a total of 7 articles, Service with a total of 5 articles, and Information Technology (IT) with a total of 3 articles.

\subsection{The Analytic Hierarchy Process (AHP) methodology}

In this study, the AHP approach is used to develop a supplier selection model for operational vehicle providers. AHP is the most widely used methodology for supplier selection; however, it becomes very complex with many alternative suppliers. To overcome this complexity, the weight cum rating method is used to first shortlist the suppliers in this study. In this method, different weights are assigned to different criteria by the experts. The suppliers are then rated by a common scale for each criterion. The next step is to calculate the overall suppliers' rating that can be done by multiplying the weight of criteria to the supplier rating for the criteria and cumulate it for all criteria of a specific supplier.

For example, the rating of Supplier 1 can be calculated by the given formula:

$R_{1}=w_{1} r_{11}+w_{2} r_{12}+w_{3} r_{13}$ 
The Weight Cum Rating method described in Table 1.

\begin{tabular}{|c|c|c|c|c|}
\hline \multirow{2}{*}{$\begin{array}{l}\text { Criteria } \rightarrow \\
\text { Weights } \rightarrow \\
\text { Suppliers } \downarrow\end{array}$} & Criteria 1 & Criteria 2 & Criteria 3 & \multirow{2}{*}{$\begin{array}{c}\text { Supplier's } \\
\text { Rating }\end{array}$} \\
\hline & $w_{1}$ & $w_{2}$ & $w_{3}$ & \\
\hline$S_{l}$ & $r_{I I}$ & $r_{12}$ & $r_{31}$ & $\sum r_{l i} w_{i}$ \\
\hline$S_{2}$ & $r_{2 l}$ & $r_{22}$ & $r_{23}$ & $\sum r_{2 i} w_{i}$ \\
\hline$S_{3}$ & $r_{31}$ & $r_{32}$ & $r_{33}$ & $\Sigma r_{3 i} w_{i}$ \\
\hline$S_{4}$ & $r_{41}$ & $r_{42}$ & $r_{43}$ & $\Sigma r_{4 i} w_{i}$ \\
\hline $\begin{array}{ll}S_{5} & \\
& \\
& \\
\text { structur }\end{array}$ & $\begin{array}{l}r_{5 I} \\
\text { te AHP a } \\
\text { d hierarchi }\end{array}$ & $\begin{array}{l}r_{52} \\
\text { proach, the } \\
\text { ally at dif }\end{array}$ & $\begin{array}{c}r_{53} \\
\text { decision } \\
\text { rent } \dddot{\text { levels }}\end{array}$ & $\begin{array}{l}\text { 2risi } \\
\text { roblem is } \\
\text { with each }\end{array}$ \\
\hline \multicolumn{5}{|c|}{$\begin{array}{l}\text { level consisting of a finite number of decision elements. } \\
\text { The upper level of the hierarchy represents the overall } \\
\text { goal, while the lower level consists of all possible } \\
\text { alternatives. One or more intermediate levels embody the } \\
\text { decision criteria and sub-criteria [5]. Figure } 1 \text { describes } \\
\text { the structure of AHP. }\end{array}$} \\
\hline
\end{tabular}

AHP uses pair-wise comparison of the same hierarchy elements in each level using the Saaty-scale, indicating the importance of one element over another element with respect to the higher-level element. The scaling process yields a relative priority or weights of elements with respect to the criterion or element of the highest level. The comparison is performed for all elements in a level with respect to all elements in the level above. The final and global weights of the elements at the lowest level of the hierarchy are found by adding all the contributions of the elements in a level with respect to all elements in higher level. The AHP includes procedures and principles used to synthesize the many judgments to drive priorities amount criteria and subsequently for alternative solutions. Once the pair-wise comparison of alternatives or sub-criteria is made with respect to elements in a higher criterion, the largest eigenvalue $\left(\lambda_{\max }\right)$ should be approximately equal to the number of elements in the comparison matrix (n). The deviation of $\lambda_{\max }$ from $\mathrm{n}$ is a measure of the consistency of judgment of the decision-maker. The Consistency Index (CI) is found using:

$$
\mathrm{CI}=\left(\lambda_{\max }-n\right) /(n-1)
$$

The consistency ratio (CR) is found using:

$$
\mathrm{CR}=\mathrm{CI} / \mathrm{RI}
$$

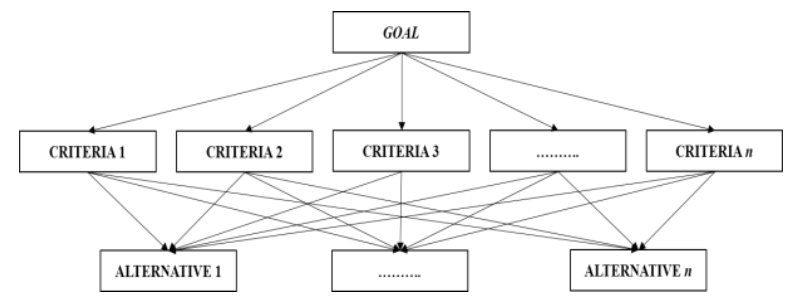

Figure 1 Structure of AHP
RI is a Random Index of the same order matrix as described in Table 11.

\section{RESULTS}

After defining the problem and identifying the criteria used, the next step is to separate the main problem into a complete elements (decomposition phase). In the AHP method, the criteria value of a study is arranged in a hierarchical form. The criteria in this study are the criteria used by companies in selecting suppliers obtained from the results of literature reviews using the Systematic Literature Review method, which are Quality, Delivery, Cost, Service, and Information Technology (IT).

Supplier selection criteria were determined based on the review of prior literature and semi-structured focus group discussion undertaken with 1 manager, and 4 senior workers from relevant departments including purchasing and procurement. Figure 2 shows the structuring of the hierarchy of the supplier selection problem, which includes two levels. The top-level of the hierarchy represents the ultimate-goal of the problem, while the second level of the hierarchy consists of five main supplier selection criteria, which are namely Quality, Delivery, Cost, Service, and Information Technology (IT). Finally, the bottom level of the hierarchy represents the alternative suppliers that should be chosen. To maintain the confidentiality of the supplier companies, the suppliers in this study are listed only using their initials. The alternative supplier in this study are PAR as alternative 1, SMR as alternative $2, \mathrm{PMS}$ as alternative 3, and PM as alternative 4 .

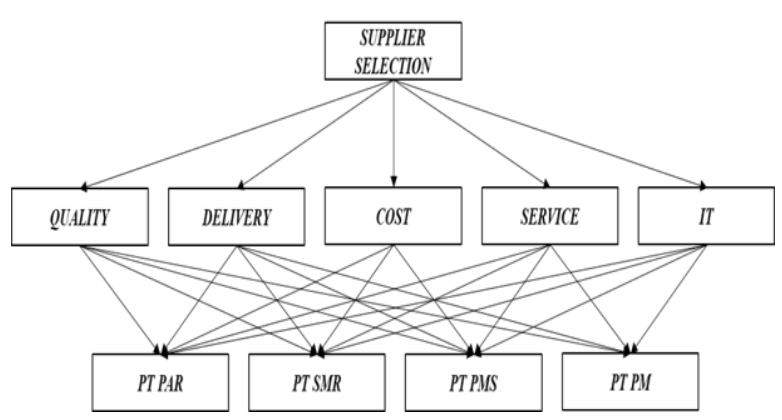

Figure 2 AHP Model for Supplier Selection

\subsection{Selected Criteria}

Based on the literature review and interaction with the case company, there are five criteria chosen for suppliers' selection in this study. The descriptions of the criteria used in this study are as follows.

Quality is closely related to the end-use of the product. Good quality products must meet minimum standards and customer requirements and perform 
efficiently, consistently and satisfy customers. The quality of a product in this study is associated with the accuracy of the goods and services with specified specifications, the quality and capacity guarantee of the goods and services, and the capability in providing consistent quality of goods and services.

The suppliers can also be rated with respect to the delivery term. Every customer expects to receive supplies at the right time with good packaging. Good packaging is essential for protection of goods against pilferage, damage, and deterioration. The delivery in this study is associated with the capability to supply goods / services in accordance with the agreed time, and the reliability in handling the shipping transportation process.

The cost of the product is also a very important decision criterion for supplier selection. Logistic costs are also associated with the product; the total cost is a sum of the cost of the product and logistic costs associated with it. Sometimes, some discount also attracts the customer. The cost in this study is associated with the price match with the quality of goods / services offered, and the capability in providing discounted prices for goods / services.

Service is focused on after-sales service because service not only provides a competitive advantage but also contributes significantly to profitability. After-sales service is expected to satisfy the company and influence future purchase intentions. The services provided by the supplier in this study is associated with the ease of contact, the apability in conveying information clearly and easily to be understood, the guaranteed warranty, and the policy in claim process.

Implementation of IT is expected to support productivity for more effective and efficient goods/ services. The use of integrated systems as well as customer data security becomes more value on the ability of suppliers. The IT provided in this study is associated with customers data security, and the scalability and system stability.

\subsection{Selection of Best Supplier Using AHP Methodology}

To shortlist the suppliers, the criteria were considered. First, the experts were given a chance to express the preferences among criteria. The experts expressed their preferences between each pair of criteria verbally as equally important, moderately more important, strongly more important, very strongly more important, and extremely more important. Subsequently, by applying Saaty's 1-9 scales, these preferences were quantified and a pair-wise comparison matrix structured. The next step is to derive the weights for each criterion. The pairwise comparison matrix provides an illustration of the relative contribution of the influence of each element to each of the criterion objectives which are one level above the level.

AHP methodology was used for selecting the best supplier among the 4 shortlisted suppliers. The proposed AHP structure is illustrated in Figure 2. Pair-wise comparisons were done to include all the combinations of criteria and alternative relationships. The criteria are compared by assessing corresponding numerical values based on the relative importance of the alternatives under consideration of their parent criteria in decision hierarchy. In the first level, each supplier selection criterion had first been compared against other criteria. In the same manner, other levels of pair-wise comparisons matrixes were also formed. The inputs of the pair-wise comparison matrix were experts' preferences of the criterion over other criteria.

Once the pair-wise comparison matrixes are formed, the next step is to derive the local weights of criteria and alternatives. The first-level computation results indicate that Service is the most important factor for supplier selection with a priority of 0.30897 and Cost is the second most important factor with a priority of 0.29418 . Quality is the third most important factor with a priority of 0.21974. Delivery is the fourth most important factor with a priority of 0.11343 . and IT is the fifth most important factor with a priority of 0.06368 . Table 2 shows the pair-wise comparison matrix for the first level of the model.

Table 2. Pair-wise comparison matrix (first level)

\begin{tabular}{|c|c|c|c|c|c|c|}
\hline Goal & Quality & Delivery & Cost & Service & IT & Priorities \\
\hline Quality & 1.00 & 3.00 & $1 / 2$ & 1.00 & 3.00 & 0.21974 \\
\hline Delivery & $1 / 3$ & 1.00 & $1 / 3$ & $1 / 5$ & 4.00 & 0.11343 \\
\hline Cost & 2.00 & 3.00 & 1.00 & 1.00 & 3.00 & 0.29418 \\
\hline Service & 1.00 & 5.00 & 1.00 & 1.00 & 5.00 & 0.30897 \\
\hline IT & $1 / 3$ & $1 / 4$ & $1 / 3$ & $1 / 5$ & 1.00 & 0.06368 \\
\hline
\end{tabular}

$\mathrm{CR}=0.09285$

Finally, each pair of alternatives is pairwise compared with one another with respect to each criteria. In comparing four supplier alternatives it is determined which alternative is preferred with respect to each criterion. Local weights of Alternative Suppliers to all Criteria are shown in the last columns of Tables 3-7. At this stage, the final priority value from the highest to lowest value will be ordered.

The final priority value is obtained from the sum of the multiplication values of each alternative priority scale against the criteria with the priority value of each criterion. Table 8 describes the Priority Value for Alternative Supplier Selection. 
Table 3. Pair-wise comparison alternatives supplier to criteria (Quality)

\begin{tabular}{|c|c|c|c|c|c|}
\hline \multirow{2}{*}{$\begin{array}{l}\text { Alternative } \\
\text { Suppliers }\end{array}$} & \multicolumn{4}{|c|}{ Quality } & \multirow{2}{*}{ Priorities } \\
\hline & PAR & SMR & PMS & PM & \\
\hline PAR & 1.00 & $1 / 3$ & $1 / 3$ & 2.00 & 0.13054 \\
\hline SMR & 3.00 & 1.00 & $1 / 2$ & 5.00 & 0.30964 \\
\hline PMS & 3.00 & 2.00 & 1.00 & 5.00 & 0.48595 \\
\hline PM & $1 / 2$ & $1 / 5$ & $1 / 5$ & 1.00 & 0.07388 \\
\hline
\end{tabular}

Table 4. Pair-wise comparison alternatives supplier to criteria (Delivery)

\begin{tabular}{|c|c|c|c|c|c|}
\hline \multirow{2}{*}{$\begin{array}{l}\text { Alternative } \\
\text { Suppliers }\end{array}$} & \multicolumn{4}{|c|}{ Delivery } & \multirow{2}{*}{ Priorities } \\
\hline & PAR & SMR & PMS & PM & \\
\hline PAR & 1.00 & $1 / 2$ & $1 / 3$ & 2.00 & 0.15687 \\
\hline SMR & 2.00 & 1.00 & 1.00 & 5.00 & 0.35760 \\
\hline PMS & 3.00 & 1.00 & 1.00 & 5.00 & 0.40888 \\
\hline PM & $1 / 2$ & $1 / 5$ & $1 / 5$ & 1.00 & 0.07665 \\
\hline
\end{tabular}

Table 5. Pair-wise comparison alternatives supplier to criteria (Cost)

\begin{tabular}{|c|c|c|c|c|c|}
\hline \multirow{2}{*}{$\begin{array}{l}\text { Alternative } \\
\text { Suppliers }\end{array}$} & \multicolumn{4}{|c|}{ Cost } & \multirow{2}{*}{ Priorities } \\
\hline & PAR & SMR & PMS & PM & \\
\hline PAR & 1.00 & $1 / 3$ & $1 / 5$ & $1 / 2$ & 0.09594 \\
\hline SMR & 3.00 & 1.00 & 2.00 & 2.00 & 0.41395 \\
\hline PMS & 5.00 & $1 / 2$ & 1.00 & 2.00 & 0.31303 \\
\hline PM & 2.00 & $1 / 2$ & $1 / 2$ & 1.00 & 0.17708 \\
\hline
\end{tabular}

Table 6. Pair-wise comparison alternatives supplier to criteria (Service)

\begin{tabular}{|c|c|c|c|c|c|}
\hline \multirow{2}{*}{$\begin{array}{l}\text { Alternative } \\
\text { Suppliers }\end{array}$} & \multicolumn{4}{|c|}{ Service } & \multirow{2}{*}{ Priorities } \\
\hline & PAR & SMR & PMS & PM & \\
\hline PAR & 1.00 & $1 / 2$ & $1 / 7$ & 3.00 & 0.10385 \\
\hline SMR & 2.00 & 1.00 & $1 / 2$ & 7.00 & 0.24646 \\
\hline PMS & 7.00 & 2.00 & 1.00 & 5.00 & 0.58969 \\
\hline PM & $1 / 3$ & $1 / 7$ & $1 / 5$ & 1.00 & 0.06000 \\
\hline
\end{tabular}

Table 7. Pair-wise comparison alternatives supplier to criteria (Information Technology)

\begin{tabular}{|c|c|c|c|c|c|}
\hline \multirow{2}{*}{$\begin{array}{c}\text { Alternative } \\
\text { Suppliers }\end{array}$} & \multicolumn{3}{|c|}{ Information Technology } & \multirow{2}{*}{ Priorities } \\
\cline { 2 - 5 } & PAR & SMR & PMS & PM & \\
\hline PAR & 1.00 & $1 / 2$ & 1.00 & 2.00 & 0.22814 \\
\hline SMR & 2.00 & 1.00 & 1.00 & 3.00 & 0.36103 \\
\hline PMS & 1.00 & 1.00 & 1.00 & 2.00 & 0.28696 \\
\hline PM & $1 / 2$ & $1 / 3$ & $1 / 2$ & 1.00 & 0.12387 \\
\hline
\end{tabular}

Table 8. Priority value for alternative supplier

\begin{tabular}{|c|c|c|c|c|c|}
\hline \multirow{2}{*}{$\begin{array}{c}\text { Alternative } \\
\text { Suppliers }\end{array}$} & \multicolumn{5}{|c|}{ Priorities Values } \\
\cline { 2 - 6 } & PAR & SMR & PMS & PM & IT \\
\hline PAR & 0.13054 & 0.15687 & 0.09594 & 0.10385 & 0.22814 \\
\hline SMR & 0.30964 & 0.35760 & 0.41395 & 0.24646 & 0.36103 \\
\hline PMS & 0.48595 & 0.40888 & 0.31303 & 0.58969 & 0.28696 \\
\hline PM & 0.07388 & 0.07665 & 0.17708 & 0.06000 & 0.12387 \\
\hline
\end{tabular}

Based on these data, a calculation is made to obtain the final priority value for the selection of suppliers by multiplying the weight of criteria to the supplier rating for the criteria and cumulate it for all criteria. Based on this calculation, the highest final value of alternative suppliers will be recommended to be chosen by the company.

The final-level priority of supplier 1 (PAR) with respect to the criteria is calculated by the equation as given below:

$(0.13054 \times 0.21974)+(0.15687 \times 0.11343)+$ $(0.09594 \times 0.29418)+(0.10385 \times 0.30897)+(0.22814 \times$ $0.06368)=0.12131$

The final-level priority of supplier 2 (SMR) with respect to the criteria is calculated by the equation as given below:

$(0.30964 \times 0.21974)+(0.35760 \times 0.11343)+$ $(0.41395 \times 0.29418)+(0.24646 \times 0.30897)+(0.36103 \times$ $0.06368)=0.32952$

The final-level priority of supplier 3 (PMS) with respect to the criteria is calculated by the equation as given below:

$(0.48595 \times 0.21974)+(0.40888 \times 0.11343)+$ $(0.31303 \times 0.29418)+(0.58969 \times 0.30897)+(0.28696 \times$ $0.06368)=0.44572$

The final-level priority of supplier 4 (PM) with respect to the criteria is calculated by the equation as given below:

$(0.07388 \times 0.21974)+(0.07665 \times 0.11343)+$ $(0.17708 \times 0.29418)+(0.06000 \times 0.30897)+(0.12387 \times$ $0.06368)=0.10345$

\section{DISCUSSION}

\subsection{Research Implications}

The object of research observed and examined in this study is the supplier for passenger light vehicles. The series of procurement processes observed and examined in the selection of suppliers in this study are the procurement that has been carried out in the period of 
2016-2019. This study presents a simple and efficient procedure for selecting suppliers by rating each supplier. An AHP-based model for supplier selection has been successfully developed and applied in this study. One of the main advantages of AHP-based decision making methodology is its ability to gather information through breaking down the problems (decomposition phase) into a hierarchical structure. In this case application model consists under 5 criteria, namely Quality, Delivery, Cost, Service, and Information Technology.

\subsection{Managerial Implications}

Although the selection criteria themselves seem generic, the ranking of their relative importance and justification of the identified determinant criteria obtained from this research provide a deeper understanding of vendor selection. From a managerial standpoint, this research provides insights for decision makers to the company in selecting vendors by considering various kinds of criteria that are assessed according to the needs and criteria of the company. For the vendor companies, they can find out what aspects they need to focus on and improve from their company in order to be able to provide maximum service to their customers.

\subsection{Conclusion}

Based on the calculation data, the data shows that PMS ranks first as an alternative supplier and should be chosen by the company as the selected suppliers with a final priority value of 0.44572 . SMR ranks second as an alternative supplier with a final priority value of 0.32952 . PAR ranks third as an alternative supplier with a final priority value of 0.12131 . PM ranks fourth as an alternative supplier with a final priority value of 0.10345 . The company should choose PMS as the selected vendor. The calculation results show that alternative suppliers PMS have the highest priority value on 3 (three) criteria, including Quality with a priority value of 0.48595 , Delivery with a priority value of 0.40888 , and Service with a priority value of 0.58969 .

\section{AUTHORS' CONTRIBUTIONS}

All authors conceived and designed the study. MFT conducted the data collection, experiments, analyzed the data and wrote the paper. All authors contributed to manuscript revisions. All authors approved the final version of the manuscript and agree to be held accountable for the content therein.

\section{ACKNOWLEDGMENT}

This study is based on research conducted at oil drilling company in Indonesia. The author would like to thank all colleagues and academic support from University of Indonesia who have endlessly provided support, prayers, and guidance to the authors in writing this study. The author also wants to thank the company for providing data and allowing to conduct the research.

Finally, author would like to acknowledge with gratitude, the support and love of author's family parents, brother, and sister. They always provide support and prayer to author. This study would not have been possible without their support.

\section{REFERENCES}

[1] Jain V, Wadhwa S, Deshmukh SG. Select supplierrelated issues in modelling a dynamic supply chain: potential, challenges and direction for future research. International Journal of Production Research. 2009;47(11):3013.

[2] Chen Y-H, Chao R-J. Supplier selection using consistent fuzzy preference relations. Expert Syst Appl. 2012;39:3233-40.

[3] $\mathrm{Ba} \mathrm{K}$, Charters S. Guidelines for performing Systematic Literature Reviews in Software Engineering. 2007;2.

[4] Yadav V, Sharma MK. Multi-criteria supplier selection model using the analytic hierarchy process approach. Journal of Modelling in Management. 2016;11(1):326-54.

[5] Partovi Fariborz Y. Determining What to Benchmark: An Analytic Hierarchy Process Approach. International Journal of Operations \& Production Management. 1994;14(6):25-39.

[6] Chen A, Chih-Ying H, Wee HM. A resilient global supplier selection strategy - a case study of an automotive company. The International Journal of Advanced Manufacturing Technology. 2016;87(58):1475-90.

[7] Aya Z, Samanlioglu F. An intelligent approach to supplier evaluation in automotive sector. Journal of Intelligent Manufacturing. 2016;27(4):889-903.

[8] Sevkli M, Koh SCL, Zaim S, Demirbag M, Tatoglu E. Hybrid analytical hierarchy process model for supplier selection. Industrial Management \& Data Systems. 2008;108(1):122-42.

[9] Mathiyazhagan K, Sudhakar S, Bhalotia A. Modeling the criteria for selection of suppliers towards green aspect: a case in Indian automobile industry. Opsearch. 2018;55(1):65-84.

[10] Bag S. Service Supplier Selection using Analytic Hierarchy Process. Journal of Supply Chain Management Systems. 2016;5(3):9-16. 
[11] Hwang B-N, Chen T-T, Lin JT. 3PL selection criteria in integrated circuit manufacturing industry in Taiwan. Supply Chain Management. 2016;21(1):103-24.

[12] Chia-Nan W, Van Thanh N, Duong DH, Hanh Tuong D. A Hybrid Fuzzy Analytic Network Process (FANP) and Data Envelopment Analysis (DEA) Approach for Supplier Evaluation and Selection in the Rice Supply Chain. Symmetry. 2018;10(6).

[13] Samut PK, Erdoğan H. INTEGRATING QUALITATIVE AND QUANTITATIVE FACTORS IN SUPPLIER SELECTION AND PERFORMANCE EVALUATION. South African Journal of Industrial Engineering. 2019;30(2):14660.

[14] Stević Ž, Vasiljević M, Puška A, Tanackov I, Junevičius R, Vesković S. Evaluation of suppliers under uncertainty: a multiphase approach based on fuzzy AHP and fuzzy EDAS. Transport. 2019;34(1):52-66.

[15] Secundo G, Donato M, Esposito E, Passiante G. Supporting decision-making in service supplier selection using a hybrid fuzzy extended AHP approach. Business Process Management Journal. 2017;23(1):196-222. 


\section{APPENDIX}
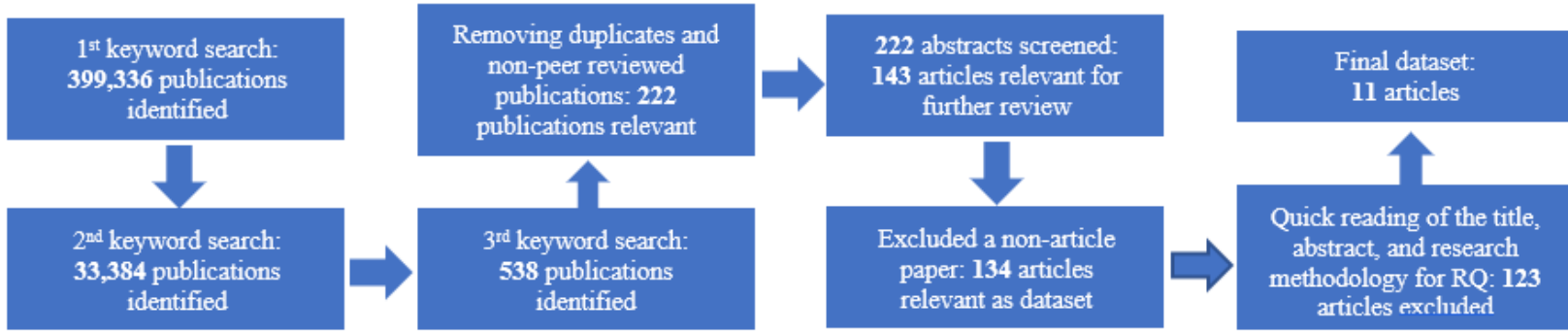

Figure 1 Article Search and Evaluation Process

Table 9. Literature on supplier selection and the analysis approaches

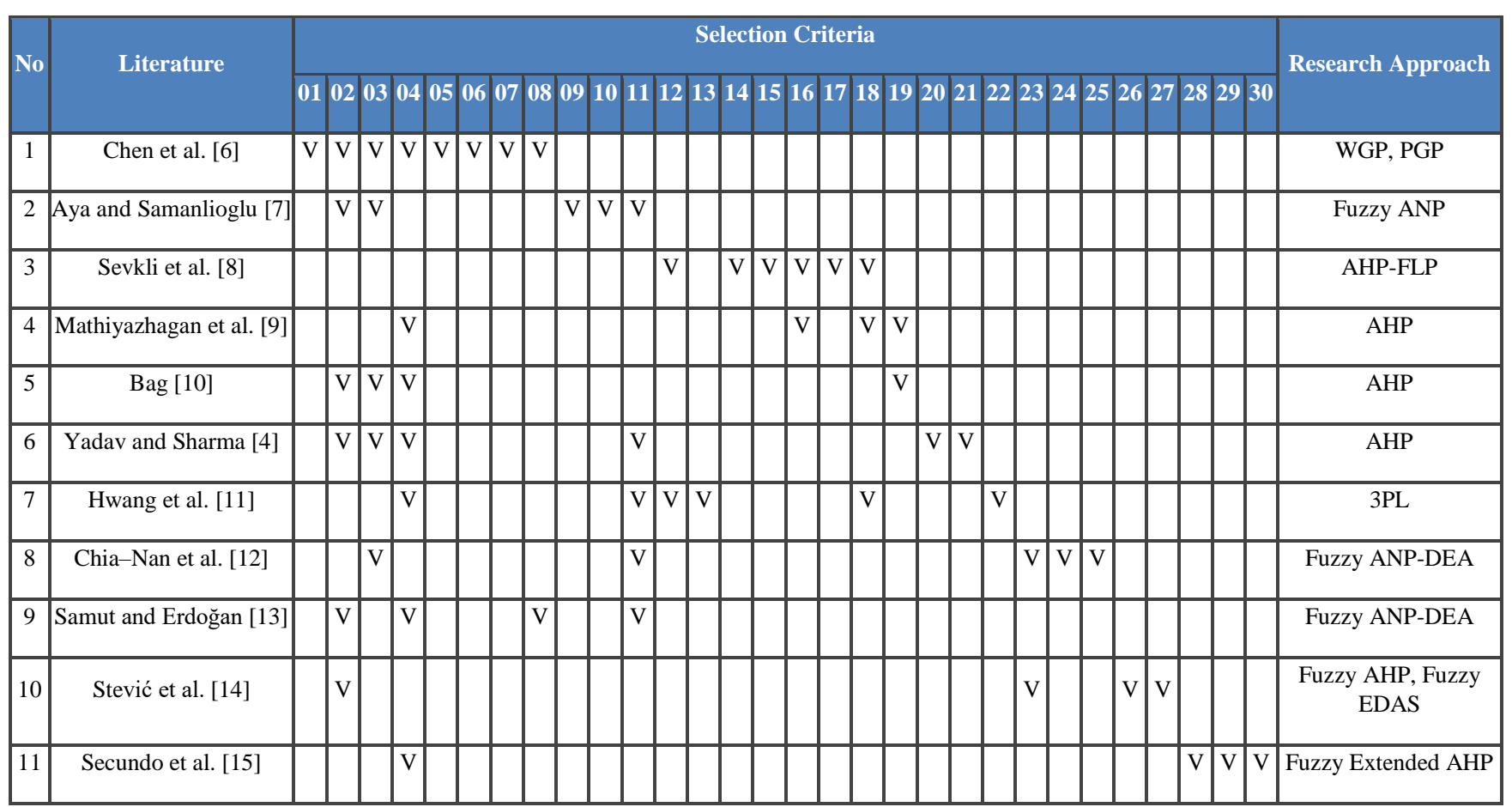

Table 10. List of selection criteria

\begin{tabular}{|c|c|c|}
\hline No & CRITERIA & Total \\
\hline 1 & Safety & 1 \\
\hline 2 & Quality & 6 \\
\hline 3 & Delivery & 5 \\
\hline 4 & Cost & 7 \\
\hline 5 & People & 1 \\
\hline 6 & Environment & 1 \\
\hline 7 & Cash Flow & 1 \\
\hline 8 & Risks & 2 \\
\hline 9 & Profile & 1 \\
\hline 10 & Pricing & 1 \\
\hline 11 & Service & 5 \\
\hline
\end{tabular}




\begin{tabular}{|c|c|c|}
\hline 12 & Performance & 2 \\
\hline 13 & Quality Assurance & 1 \\
\hline 14 & Human Resources & 1 \\
\hline 15 & Quality System Assessment & 1 \\
\hline 16 & Manufacturing & 2 \\
\hline 17 & Business Criteria & 1 \\
\hline 18 & Information Technology & 3 \\
\hline 19 & Management & 2 \\
\hline 20 & Long term relationship & 1 \\
\hline 22 & Flexibility & 1 \\
\hline 23 & Intangible & 1 \\
\hline 24 & Financial & 2 \\
\hline 25 & Environmental Management System & 1 \\
\hline 26 & Logistics & 1 \\
\hline 27 & Communication and Business & 1 \\
\hline 28 & Maintainability & 1 \\
\hline 29 & Portability & 1 \\
\hline 30 & Supplier Characteristics & 1 \\
\hline
\end{tabular}

Table 11. Random Index (RI)

\begin{tabular}{|c|c|c|c|c|c|c|c|c|c|c|c|c|}
\hline No. & $\mathbf{1}$ & $\mathbf{2}$ & $\mathbf{3}$ & $\mathbf{4}$ & $\mathbf{5}$ & $\mathbf{6}$ & $\mathbf{7}$ & $\mathbf{8}$ & $\mathbf{9}$ & $\mathbf{1 0}$ & $\mathbf{1 1}$ & $\mathbf{1 2}$ \\
\hline RI & 0 & 0 & 0.58 & 0.9 & 1.12 & 1.24 & 1.32 & 1.41 & 1.45 & 1.49 & 1.15 & 1.58 \\
\hline
\end{tabular}

